\title{
DISECCIONES DISCURSIVAS DEL CUERPO DE LA MUJER INDÍGENA EN EL DERECHO CONSTITUCIONAL MEXICANO
}

\author{
Alma Guadalupe Melgarito Rocha ${ }^{1}$
}

\begin{abstract}
Resumen
El artículo se propone analizar — merced al uso de recursos semiológicos-, la modelización del cuerpo de las mujeres indígenas en la Constitución Mexicana, desde la perspectiva de la Crítica Jurídica entendida como análisis discursivo. Bajo la premisa de que el discurso del derecho muestra a la vez que oculta, el análisis pretende develar las heridas infligidas en los cuerpos de las mujeres indígenas en el texto legal, heridas que el discurso del derecho encubre bajo un velo de igualdad, estado garante, protección y ciudadanía pluricultural.
\end{abstract}

Palabras clave: Crítica Jurídica; Semiología; Discurso del derecho; Mujer indígena; Constitución.

\section{INTRODUCCIÓN}

Somos el lenguaje. Y el lenguaje legal construye un mundo de ficción donde la realidad se ve desplazada. El discurso del derecho disfraza de justicia la ilusión del no conflicto. Construye la máscara de un sujeto autónomo que es "libre", "neutral", "universal". Así, los enfrentamientos de intereses opuestos y en contradicción deben ser ocultados y, para ello, el derecho crea un mundo de ficción para que en caso de que la contradicción produzca una herida, éste sea capaz de reconducir la máscara, nombrando un espacio de lo que es, pero desplazándolo al tiempo a un lugar diferente en el que la máscara pueda sobrevivir, reajustarse, y mostrar, de nuevo, el mundo ficticio revivido.

El derecho oculta al tiempo que muestra. Muestra el espejo deforme de una sociedad igualitaria, del reconocimiento de la otredad, del espacio democrático, de la ciudadanía multicultural. Y oculta las heridas reales provenientes de la desigual distribución de las condiciones materiales de existencia, de las diferencias de clase, de género, de raza. Porque el derecho es la descripción de la apariencia de las relaciones sociales (Correas, 2005)

En medio del desmembramiento discursivo que presenta la realidad deformada por el discurso del derecho, los cuerpos son redistribuidos, resignificados en el montaje de ficción. Y los cuerpos de las mujeres sitiados, diseccionados, confinados, sujetados. Así, el derecho abre el telón. Y la explotación sexual emerge como derecho

\footnotetext{
${ }^{1}$ Doctora en derecho por la universidad nacional autónoma de México. Profesora titular de tiempo completo en la Universidad Autónoma de Ciudad Juárez. E-mail: almamelgarito@gmail.com
} 
de familia. Y el despojo y la violencia colonial saltan disfrazados de protección estatal, de monopolio del poder punitivo, de monopolio de la producción jurídica.

¿Qué máscara envuelve el cuerpo diseccionado de la mujer indígena mediante el derecho? ¿Cómo describe el discurso legal la apariencia de la explotación sexual, racial, y de clase? En este breve ensayo delinearemos algunos trozos discursivos que apuntan hacia posibles repuestas a estas preguntas. Dividiremos el estudio en tres partes. En la primera abordaremos la mirada teórica y metodológica de la que partimos. En la segunda analizaremos el tratamiento constitucional de la relación estado-comunidad y pueblos indígenas. Finalmente, en la tercera nos dedicaremos al análisis jurídico de la disección discursiva de la mujer indígena en el artículo segundo constitucional.

\section{LA CRÍTICA JURÍDICA COMO DEVELAMIENTO SOCIO-SEMIOLÓGICO}

El discurso jurídico, como todo discurso, y como todo producto humano, porta ideología, y tiene la característica de hacer un prototipo de sujeto: aquel que cree lo que dicho discurso le dice. Este sujeto se transformará en una cadena de transmisión de ideología -la del derecho, por caso- que recibe a través de enunciados normativos, constituyéndose no sólo en su reproductor, sino también en su defensor y en el velador de lo que ese discurso mandata. Este sujeto hace la máscara del derecho, y del contexto legal con sus propias palabras, y con sus propias acciones particulares. El discurso del derecho es el medio a través del cual se materializan las pretensiones del emisor de la norma de controlar los comportamientos de los destinatarios de la misma. Estas pretensiones, por supuesto, responden a su ideología, es decir, a su particular "modo de ver la realidad". Por su parte, el (los) destinatario(s) de la norma asume(n) como suyo el actuar que la norma le(s) impone, y, al hacerlo, al internalizar como propio, y además, como correcto el actuar que otro(s) le(s) impone(n) y actuar luego en consecuencia, reproduce(n) la ideología jurídica hegemónica, poniendo con esto en marcha la maquinaria del derecho como reproductor de ideología y como el orden coactivo de la conducta humana. Esto es, todos hacemos al derecho y al estado en actos de habla cotidianos.

Así, este ensayo tiene cimientos en los estudios hechos desde la Crítica Jurídica entendida como una disciplina científica que se encuentra en los límites entre la Sociología y la Semiótica jurídicas. Sin duda, esta manera de entender la disciplina es tributaria de la mirada de Óscar Correas, quien apoyándose en los estudios de Gramsci sobre el papel de los intelectuales en la construcción de la hegemonía, propone entender la Crítica Jurídica desde el punto de vista externo como una crítica del papel de la pseudociencia jurídica en la reproducción de la sociedad capitalista en general. Nosotros agregamos que no sólo de la ciencia, sino de toda producción de conocimiento acerca del fenómeno jurídico que tenga por objetivo hacer pasar por científico o legítimo el principio de autoridad jerárquica, cuna de toda desigualdad humana. Este es el nivel de la crítica en que nos 
situaremos. Se trata, como dijimos, de una propuesta que tiene la pretensión de instalarse en el nivel de las Ciencias Sociales. En lo siguiente trataremos algunos conceptos base del estudio.

\section{Connotación y denotación}

La particularidad del lenguaje de transmitir diversos sentidos, y en particular, del lenguaje jurídico de transmitir sentidos diversos de aquél del cual se ocupa y reconoce la Ciencia jurídica puede clarificarse merced al uso de los conceptos de connotación y denotación. Si aceptamos que es posible identificar sistemas significantes diversos en el interior de los textos, entonces será posible aceptar también que la función de transmisión de la ideología puede cumplirse con la presencia de un solo elemento en un discurso, con la sola condición de que el receptor reconozca el código que sirve para identificar ese elemento como parte del sistema ausente. Y estos sistemas significantes podrían estar connotados, o bien denotados en el texto.

En una primera aproximación al concepto podemos decir que el uso denotativo de un vocablo consiste en emplearlo para designar aquella idea que, conforme con el código usual es la que debe ser designada con ese vocablo. Mientras que el uso connotativo consiste en emplearlo para designar una idea distinta de la que se designa con su uso denotativo. En este último caso se le imprime un nuevo valor semántico al término, el cual es diferente de su significación originaria. Aunque, claro está, el uso denotativo es más fácilmente reconocible por el lector en un texto. Esto significa que para el caso del uso denotativo nos encontramos simplemente ante un signo lingüístico en su más pedestre función de unir un significado con un significante. Pero cuando se da el caso de que este lenguaje de denotación se convierte a su vez en elemento de otro lenguaje, realizando el papel de significado contenido- nos encontramos frente a un metalenguaje. Y si realiza también el papel de significante -expresióntenemos entonces un lenguaje de connotación.

\section{Teoría generales y disciplinas científicas}

Las teorías generales son las disciplinas mediante las que los científicos construyen los conceptos que después van a utilizarse para la práctica de la ciencia de que se trate. Por ejemplo, en el derecho, la teoría general del derecho, —en adelante TGD — ofrece conceptos como norma, sistema jurídico, validez, eficacia, etcétera. Por su parte, la teoría general de la sociedad — en adelante TGS - ofrece el conjunto de conceptos teóricos que constituyen el objeto de la ciencia sociológica. Con la ayuda de las Teorías, es posible la creación de modelos con los que la ciencia pretende describir sus objetos de estudio. Dichos modelos sirven como hipótesis que el científico deberá contrastar con la información 'empírica' recopilada.

Podemos decir que los objetivos de una ciencia determinan su objeto, de modo que la teoría se preocupa por producir conceptos que luego son el objeto científico, según y conforme con los intereses que comandan las 
preocupaciones de los científicos. Es por eso que tanto TGD como TGS hay muchas ${ }^{2}$... puesto que lo es 'la realidad' depende de la teoría elegida. Aquí nos valemos de una TGD y una TGS de inspiración kelseniana, marxista y anarquista. Conforme avancemos en la exposición desarrollaremos su contenido, paralelamente a la manera en que echamos mano de sus conceptos y categorías para lograr los fines de nuestra investigación.

Para poder llevar adelante nuestra investigación precisaremos acudir también a una Teoría Sociológica General del Derecho (TSGD), que es la disciplina que nos brinda los conceptos necesarios para la Sociología Jurídica (SJ). La Sociología Jurídica es la disciplina que se esfuerza por explicar las causas y efectos del derecho. Sin embargo, recordemos que la postura escéptica enfoca sus reflexiones a la destrucción de la idea de la causa, y que desde esta visión de mundo decimos que existe una distancia infranqueable entre lo que llamamos 'realidad' y el 'discurso que habla de esa realidad'. De modo tal que lo que la sociología llama causa, para la semiología resultan ficciones. Nosotros diremos simplemente que la causa de la que habla la Sociología Jurídica es, también, un discurso. Esto significa que, en el fondo, todas las llamadas disciplinas científicas (en la medida en que la ciencia se sustenta en la idea de la causa), son no más que grandes castillos construidos con cimientos de barro. Pero no es menos cierto que es posible esforzarse por tender algunos 'puentes' entre ambos y precisamente esa es la tarea de la SJ.

Podemos ver que para realizar nuestro estudio será necesaria la concurrencia de distintas disciplinas científicas: la Sociología Jurídica, la Semiología Jurídica, la Crítica Jurídica, la Ciencia del Derecho.

\section{Teoría sociológica general del derecho (tsgd)}

La TSGD nos dota de los conceptos necesarios para la Sociología Jurídica. En nuestro caso, para una Sociología Jurídica Crítica. La TSGD es 'general' pues pretende dar respuesta a preguntas que se plantean para 'cualquier tipo' de sociedad. Y bien, ¿qué es una sociedad? ¿Cuándo a un conjunto de seres humanos es dable otorgarle el sentido de «sociedad»? Una respuesta que consideramos sugerente es la Hans Kelsen, para quien "todo sistema social es un orden y todo orden es un conjunto de normas."(Kelsen 1969) De modo que toda sociedad puede verse como un conjunto de normas. Esto significa que para Kelsen, lo que autoriza a llamar a un conglomerado de seres humanos como 'sociedad', es el hecho — la observación — de que ese conjunto de seres humanos se encuentra ordenado de conformidad con un mismo sistema normativo. Ahora bien, nos dice Kelsen, esta observación podría hacerse conforme el principio de imputación o bien, conforme el principio de causalidad, donde la primera actitud funda la Dogmática jurídica y la segunda la Sociología. Como puede comprenderse, la Sociología Jurídica es tributaria de ambas ciencias, pues en primer lugar es necesario descifrar de entre el continuo

\footnotetext{
${ }^{2}$ Acerca de la Teoría general del derecho, así como de la Teoría Social a las que me adscribo, recomiendo la lectura de mi Pluralismo Jurídico (2012), ya que por razones de espacio he seleccionado para su aparición en este texto sólo algunos de los
} 
discursivo aquel que corresponde con el discurso del derecho, para después preguntarse si desde el punto de vista de la causalidad, las conductas empíricamente observadas pueden ser vistas como causas y efectos de ese discurso.

Ahora bien, la pregunta fundamental de la Sociología Jurídica es ¿por qué en tal sociedad se ordenan o prohíben tales conductas y no otras? ¿Es que la causa del derecho son las relaciones sociales? o ¿es el derecho la causa de las relaciones sociales? La manera en que la Sociología Jurídica ofrece respuestas a estas preguntas es mediante la elaboración de modelos teóricos que sirven como hipótesis que el científico deberá contrastar con la información 'empírica' recopilada. En este apartado nos dedicaremos a plantear la base teórica que permitirá la construcción de nuestros modelos. Recordemos que hemos dicho que solamente profundizaré en esta ocasión en aquellos conceptos y categorías no suficientemente desarrollados en mis trabajos anteriores.

\section{Radical e irreparable heterogeneidad ontológica}

Pensamos que existe una radical escisión entre el mundo de los hechos y el mundo del sentido, o entre el discurso y su referente, o entre el discurso del derecho y el fondo ontológico, ya que a este último tenemos acceso solamente a través del análisis de los discursos. De esta manera, aquí aceptaremos que el referente es «aquello del mundo exterior respecto de lo cual el hablante pretende decir algo», pero que ese 'algo', será, siempre, otro discurso.

Si partimos de esa radical escisión, ¿cómo podemos hacer un estudio de la manera como las relaciones sociales son la causa o efecto del derecho? precisamente la Sociología Jurídica es una disciplina que se esfuerza en 'tender puentes' entre ambos mundos. En este punto nos adherimos a la propuesta teórica que para una Sociología Jurídica Crítica nos propone Oscar Correas. En lo siguiente haremos una breve exposición del núcleo de su análisis.

De conformidad con Correas (2005), un sociólogo del derecho ingenuo construye su cuerpo teórico merced a la premisa de que las relaciones sociales (o los hechos sociales, dependiendo de la teoría sociológica seleccionada), son la causa de que en el derecho se encuentren como obligatorias «0» o como prohibidas «V» ciertas conductas. $\mathrm{O}$, en otras palabras, que para el sociólogo ingenuo el referente del derecho son las relaciones sociales. Sin embargo, Correas replica este tipo de Sociología Jurídica diciendo que "el referente no es sino el discurso que describe la apariencia de esa relaciones." (Correas 2004)

Para comprender los alcances de esta expresión precisamos incorporar aquí algunos conceptos acuñados por Correas que son la base de su Teoría Crítica del Derecho. Para este autor, el discurso del derecho está compuesto por una gran cantidad de partes o sectores, cuyas células son enunciados, unidades mínimas de sentido, y el interior de cada enunciado, podemos distinguir al menos dos tipos de sentidos: el deóntico y el 
ideológico.

El sentido deóntico del discurso del derecho es aquel que todo intérprete del discurso del derecho encuentra como norma, esto es, como enunciado cuyo sentido es lo permitido «p», lo obligatorio, «0», o lo prohibido «V». Aquí, Correas hace uso de la lógica jurídica para aislar al sentido deóntico de toda 'otra ideología' que contenga el discurso. Luego, el sentido deóntico del derecho consiste en las normas que el intérprete del discurso del derecho 'encuentra' y que consisten en la modalización deóntica de la descripción de una conducta. Por su parte, el sentido ideológico del derecho consiste en todo aquel 'otro sentido' que se actualiza en el discurso del derecho que no es reductible a normas (modalizaciones deónticas de las descripciones de conductas).

Para Correas, el sentido deóntico del derecho NO tiene referente, pero el sentido ideológico Sí lo tiene, por lo que es el sentido ideológico el que habla del mundo. El mismo autor nos propone el siguiente ejemplo, pensemos en un enunciado del discurso del derecho que diga:

\section{Obligatorio detenerse cuando el semáforo esté en color rojo}

Este enunciado puede representarse haciendo uso de una nomenclatura lógica $\ll 0 p »$, donde $\ll 0 »$ es el modalizador deóntico 'Obligatorio', y «p» es la descripción de la conducta 'detenerse cuando el semáforo esté en rojo'. Pues bien, el sentido deóntico de este enunciado puede ser leído como «Op». Pero para Correas, ese 'Obligatorio detenerse' no tiene referente. Las palabras 'semáforo' y 'rojo', sí lo tienen, pero «Op» NO. Hasta ahora, podemos resumir su propuesta de la siguiente manera: es el análisis del discurso del derecho, la Crítica Jurídica, la que nos muestra que el sentido ideológico del derecho constituye una 'distorsión, ficción o apariencia', y es precisamente este convencimiento lo que lo aleja el análisis de la Sociología Jurídica que llama ingenua porque ésta no advierte que las 'verdaderas' relaciones sociales son, en realidad, discursos, y esta ingenuidad es la que los lleva a pensar que la causa de esa distorsión está en lo que llaman 'relaciones sociales'. Pero contrario a esa postura, nuestro autor nos muestra que "el discurso ficticio que describe la apariencia de esas relaciones sociales, constituye el referente del sentido ideológico del discurso del derecho." O mejor, que: “... el referente del sentido ideológico del derecho es el discurso distorsionador que describe la apariencia de las relaciones sociales."

Ahora bien, ies posible establecer relación de causalidad entre el sentido deóntico del derecho y ciertas relaciones sociales? A esta pregunta respondemos que Sí, pues precisamente esa es la hipótesis que funda la Sociología Jurídica. Y recordemos que ésta es una ciencia de vocación empírica cuyo objeto son las conductas relacionadas con los discursos jurídicos. Y que las causas coinciden con el referente. Por lo que esta discontinuidad impone un procedimiento de verificación que procede a la comparación de las normas positivas con las del modelo que ofrece la TSGD.

De tal modo, tal como comenzamos este punto, es mediante la TSGD que la ciencia propone modelos 
que nos ayudan a describir el conjunto de normas que sería necesario dictar para garantizar que suceda la repetición de conductas cuya descripción constituye el modelo sociológico general construido de conformidad con la TSGD seleccionada. En lo siguiente describiré, sobre la base teórica hasta aquí descrita, el análisis de la apariencia de las relaciones sociales en el discurso del artículo segundo constitucional.

\section{FIGURAS DE LA MÁSCARA LEGAL EN EL ARTÍCULO SEGUNDO CONSTITUCIONAL: LOS PUEBLOS INDÍGENAS EN LA REPRESENTACIÓN TEATRAL}

En los materiales jurídicos llamados «constitucionales» reconocemos una serie de enunciados en forma prescriptiva que generan funciones, legitiman acciones y autorizan determinaciones: en el texto se advierte la caracterización del ejercicio del poder a través del discurso. El discurso del derecho realiza la distribución de roles en la sociedad para legitimar autorizando. La creación de organismos, la determinación de sus funciones, el reconocimiento de funcionarios, la concesión de autoridad a personas y colectivos, todo el aparato estatal se construye merced a este discurso. O dicho en inmejorable argumentación:

[...] (las) reglas sobre la formación del lenguaje jurídico tienden no a establecer las condiciones gramaticales, semánticas o lógicas que una determinada expresión debe satisfacer para integrar un sistema aplicable de normas jurídicas válidas, sino que, se limita a aludir a quién, en qué condiciones de procedimiento, está autorizado y/o capacitado y/o en situación tal como para producir expresiones válidas al sistema, que a su vez designarán nuevos individuos capaces de hacer otro tanto, estableciendo un orden de relación jerárquica entre los sujetos de producción del discurso y entre las expresiones de ese discurso El discurso jurídico es el discurso del ejercicio del poder y, por ende, alude e identifica a aquellos que pueden producirlo, configurando la noción de autoridad u órgano y ordenando las relaciones recíprocas de los productores de ese discurso del poder entre sí, y de éstos con el resto de los individuos actuantes en relación a una determinada institución social, con la mediación del discurso jurídico. (Entelman,1982)

Las cursivas son mías. Esto es, el discurso del derecho marca la forma en que debe ejercerse el poder al ordenar jerarquías y al señalar a aquellos que están en condiciones de producirlo. Pero no sólo eso. También señala a los individuos capacitados para usar o decir ese discurso. El discurso no sólo designa a quien produce y a quien debe leer los enunciados prescriptivos, sino que, además, señala cómo deben ser leídos, amenazando con la violencia ante su incumplimiento. Hay, entonces, sujetos reconocidos por el discurso para encontrar el sentido en los discursos que crearon otros sujetos, también designados de la misma forma. En este apartado haremos un análisis del discurso del artículo segundo constitucional (en adelante CPEUM, Art.2), que trata de la relación estado-pueblos indígenas.

En cuanto a las reglas de formación del discurso, la ideología de dominación que connota el texto comienza con la estrategia de la declaración de un aparente 'consenso' que denota la idea de que la nación mexicana es 'única e indivisible', y que está basada en su 'composición pluricultural': 
[...] Artículo 2o. La Nación Mexicana es única e indivisible. La Nación tiene una composición pluricultural sustentada originalmente en sus pueblos indígenas que son aquellos que descienden de poblaciones que habitaban en el territorio actual del país al iniciarse la colonización y que conservan sus propias instituciones sociales, económicas, culturales y políticas, o parte de ellas. (CPEUM, Art.2)

Con esta estrategia, el texto logra presentar a los pueblos indígenas como 'formando parte de' la Nación Mexicana. Así, el texto hace uso de una semiótica denotativa de inclusión de los pueblos indígenas, al mismo tiempo connota la dominación de estos grupos sociales. Recordemos que precisamente uno de los reclamos que dieron origen a esta reforma fue la negación sistemática de los pueblos y comunidades indígenas en los textos normativos estatales. Y vale decir que estos reclamos continúan vigentes. El texto presenta a la nación como la forma de la composición pluricultural, pero,

[ ... ] La forma nación contemporánea, en su basamento abstracto, puede ser vista, por tanto, como el espacio social limitado correspondiente y necesario para la formación histórica del gran espacio esencial elemental del dominio de la relación de valor y de la respectiva distribución de las actividades de los individuos a escala universal general, la relación de valor, pues sólo ella permite afirmar y perpetuar como socialidad "natural" las formas sociales específicas distributivas del trabajo necesarias para la existencia de la forma de valor como forma específicamente social del producto y del proceso de trabajo.[... Históricamente, esta determinación lógica expresa el modo concreto del desarrollo del capitalismo-histórico centrado en áreas geográficas y sociales específicas que luego se van expandiendo como división del trabajo hasta alcanzar una dimensión mundializada en la que las relaciones de jerarquía en esta división del trabajo social han tomado la forma de colonialismo, neocolonialismo, dependencia nacional, etc. (García, 2009)

Si aceptamos esta idea, el contenido específico de la forma nación no es la composición pluricultural, sino la expresión del modo concreto del desarrollo del capitalismo centrado en áreas geográficas y sociales específicas. ¿Entonces qué circunstancia explica el esfuerzo por darle a la Nación un fundamento en la pluriculturalidad? Para responder a esta pregunta me parece pertinente recurrir a la argumentación de Duquelsky, quien, recordando a Mari (1993), reconoce en el modelo contractualista el papel de ficción fundadora del poder estatal, y nos advierte ahora que lo mismo puede decirse sobre el llamado consenso multicultural, el cual, en términos de la reforma en estudio, se advierte claramente en la llamada 'composición pluricultural de la nación'. Para Duquelsky, la remisión a la pluriculturalidad se explica por el papel de ficción re fundadora, re legitimadora, del poder estatal, y podemos decir nosotros: de búsqueda del restablecimiento de la hegemonía que el bloque en el poder había visto entrar en crisis.

Una vez establecida la nueva ficción fundadora del poder estatal, el texto procede a la distribución de los roles en el texto, y comienza con la construcción de la identidad del indígena y su cultura, que en los primeros párrafos etiqueta como principios generales. Para el texto, los pueblos indígenas son aquellos que "descienden de poblaciones que habitaban en el territorio actual del país al iniciarse la colonización y que conservan sus propias instituciones sociales, económicas, culturales y políticas, o parte de ellas." Al respecto vale recordar la tesis de Alicia Ruiz (1993) en el sentido de que "todo derecho consagra un cierto humanismo", y en el texto normativo que nos 
ocupa, frente al 'blanco' se construye la idea del 'indígena'. Precisamente los primeros párrafos de la reforma se dedican a establecer esta identificación de los actores. Por ejemplo, en el párrafo siguiente el legislador acude al auxilio de conceptos extraídos de las disciplinas antropológicas para dar un soporte 'científico' a esta caracterización. “... La conciencia de su identidad indígena deberá ser criterio fundamental para determinar a quiénes se aplican las disposiciones sobre pueblos indígenas." (CPEUM, Art. 2)

Este fragmento, además de reforzar la idea del juez como simple aplicador de la ley, estrategia merced a la cual los operadores jurídicos pueden dormir tranquilos, bien cobijados en la ideología de la objetividad de su trabajo-, el legislador delimita el ámbito de validez de la norma 'indígena'. Y con esta frase, el racismo se hizo, pues queda asegurado un desplazamiento referencial clave, a saber: a partir de esta enunciación, queda explicitado que el tan querido reconocimiento del pluralismo sólo es unilateral, pues si un indígena violara el derecho de los 'no indígenas', entonces se aplicaría el derecho de los 'no indígenas', pero jamás a la inversa. Y ya que el texto es cuidadoso en dejar claro que estas disposiciones sólo se 'aplicarán' a quienes tienen 'conciencia de su identidad indígena', luego, por virtud de esta frase las disposiciones constitucionales son blanqueadas, pues por este prodigio los 'no indígenas' pueden mantenerse a salvo, dormir tranquilos y seguros de que nunca serán juzgados por las 'normas indígenas', y, sin embargo, más adelante, el mismo texto deja claro que el derecho estatal sí puede intervenir en los sistemas indígenas, como exigencia de blanquitud.

He tomado el concepto de blanquitud de Bolívar Echeverría, quien, problematizando las pistas sugeridas por Weber (2011) en La Ética Protestante y el espíritu del capitalismo a partir del reconocimiento de ...

[...] un cierto 'racismo' constitutivo de la modernidad capitalista [...] que exige la presencia de una blanquitud de orden ético o civilizatorio como condición de la humanidad moderna, pero que en casos extremos, como el del Estado nazi de Alemania, pasa a exigir la presencia de una blancura de orden étnico, biológico y cultural (Echeverría: 2010)

... nos dice que la blanquitud es la "conciencia identitaria pseudoconcreta destinada a llenar la ausencia de concreción real que caracteriza a la identidad adjudicada al ser humano por la modernidad establecida" (Echeverría, 2010). Luego, si bien para el autor la blanquitud no es en principio una identidad de orden racial, la que llama pseudoconcreción del homo capitalisticus incluye sin duda ciertos rasgos étnicos de la blancura' del hombre blanco, aunque sólo en cuanto encarnaciones de otros rasgos de orden ético. Así,

La explicación de esta posible paradoja de una nación "de color" y sin embargo "blanca" puede encontrarse en el hecho de que la constitución fundante, es decir, primera y ejemplar, de la vida económica moderna fue de corte capitalista-puritano, y tuvo lugar casualmente, como vida concreta de una entidad política estatal, sobre la base humana de las poblaciones racial e identitariamente "blancas" del noroeste europeo. Se trata de un hecho que hizo que la apariencia "blanca" de esas poblaciones se asimilara a esa visibilidad indispensable de esa "santidad" capitalista del ser humano moderno, que se confundiera con ella. (Echeverría, 2010)

Luego, merced al uso del concepto de blanquitud, podemos develar que el texto de la reforma connota un racismo ético, que se traduce en la imposición de un 'marco constitucional de autonomía' como el grillete que 
impedirá que el derecho a la ‘libre determinación’ de los pueblos indígenas escape de la forma normativa estatal, y los valores que ésta protege:

[... El derecho de los pueblos indígenas a la libre determinación se ejercerá en un marco constitucional de autonomía que asegure la unidad nacional. El reconocimiento de los pueblos y comunidades indígenas se hará en las constituciones y leyes de las entidades federativas, las que deberán tomar en cuenta, además de los principios generales establecidos en los párrafos anteriores de este artículo, criterios etnolingüísticos y de asentamiento físico. (CPEUM, Art. 2)

Recordemos que, en el discurso jurídico, una cierta institución — conjunto de normas—, es autónoma en tanto que ciertas normas le autorizan a producir ciertas otras normas. Esto es, que quien es autónomo, puede producir normas, pero solamente aquellas para las cuales está autorizado por un sistema normativo. Luego, con este párrafo la dominación está asegurada. Esto explica la casi terca remisión constante al sentido deóntico del texto que se traduce en la $\mathrm{O}$ de los pueblos y comunidades indígenas de obedecer al derecho estatal, la cual connota la amenaza con la violencia que el estado es capaz de desencadenar en caso de desobediencia. Luego, las comunidades y pueblos indígenas estarán autorizadas a producir algunas normas, sí, pero sólo si, el estado les permite producirlas. Porque, además, la "la ley establecerá los casos y procedimientos de validación por los jueces o tribunales correspondientes". (CPEUM, Art. 2)

Es por eso que, aunque el párrafo siguiente, presenta una serie de argumentos que si bien podrían interpretarse como una confirmación de las facultades jurisdiccionales indígenas, el texto connota al mismo tiempo, esta relación de dominación:

[... ] A. Esta Constitución reconoce y garantiza el derecho de los pueblos y las comunidades indígenas a la libre determinación y, en consecuencia, a la autonomía para:

II. Aplicar sus propios sistemas normativos en la regulación y solución de sus conflictos internos, sujetándose a los principios generales de esta Constitución, respetando las garantías individuales, los derechos humanos y, de manera relevante, la dignidad e integridad de las mujeres. La ley establecerá los casos y procedimientos de validación por los jueces o tribunales correspondientes.

III. Elegir de acuerdo con sus normas, procedimientos y prácticas tradicionales, a las autoridades o representantes para el ejercicio de sus formas propias de gobierno interno, garantizando la participación de las mujeres en condiciones de equidad frente a los varones, en un marco que respete el pacto federal y la soberanía de los estados.

IV. Preservar y enriquecer sus lenguas, conocimientos y todos los elementos que constituyan su cultura e identidad. (CPEUM, Art. 2)

Así, podemos observar que la idea de la 'libre determinación de los pueblos indígenas' va tomada de la mano de la exigencia de blanquitud que se traduce en la obligación de sujeción y respeto a: 'Los principios generales de la Constitución', 'Las Garantías Individuales', 'Los Derechos Humanos', 'El Pacto Federal', 'La soberanía de los estados' y, ... 'de manera relevante la dignidad de las mujeres'. Por lo que este núcleo termina nulificando en el texto cualquier posibilidad de decisión de los pueblos y comunidades indígenas, naturalizando la radical negación constitucional del pluralismo jurídico. Ahora bien, ¿Qué quiero significar cuando digo que el sistema semiológico protector del monismo jurídico del texto connota la naturalización de la relación social de 
dominación? Esto nos lleva a la representación del cuerpo de la mujer indígena en el texto.

\section{LA DISECCIÓN CORPÓREA DE LA MUJER INDÍGENA MEDIANTE EL DISCURSO JURÍDICO}

Joaquín Herrera, (2004) citando a Clarisse Pinkola, en un muy sugerente artículo a propósito de la teoría feminista, nos remite a la idea de la existencia en toda cultura de un depredador natural, que simboliza los aspectos más devastadores de la sociedad. Este depredador — nos dice—, se instala en las mentes, en las actitudes, y en los sueños de todos los que forman parte de esa sociedad, imponiéndose como la perspectiva natural desde la que debemos percibir el mundo y las relaciones sociales desde las que nos movemos. Y, nos dice el autor, "esta dinámica instala un sistema de valores como si fuera el único que tuviera el derecho a conformar nuestras percepciones y nuestra acción" (Herrera, 2004).

En dicho artículo, para Joaquín Herrera, el depredador actúa no sólo discriminando jurídicamente, es decir, estableciendo estatus diferentes a los sexos, las etnias, las razas, o las clases, sino ocultando las causas reales de las diferencias de sexo, clase o etnia: la desigualdad material en el proceso de la división social del trabajo y la consecuente exclusión del ámbito de lo político. Desde su perspectiva, el depredador funciona, primero, como:

[...] un espejo deforme que presenta al hombre blanco y occidental, y al sistema de valores que lo protege, induciendo a los demás a sentirse humillados ante la magnificencia y la eternidad de sus privilegios. Así, la ideología del depredador se sitúa al margen de la experiencia concreta de los seres humanos a los que devora. Instaura una verdad abstracta y rechaza todo lo que no se corresponda con ella. (Herrera, 2004)

Y, segundo, ocultando que el modo más efectivo de escaparnos de esa imagen deformada de la realidad es huir de las idealizaciones y abstracciones de, por ejemplo, 'lo femenino' natural o el 'buen indígena'. Para Joaquín Herrera, es posible entender la base y el sustento de todo tipo de dominación totalitaria o autoritaria merced al uso de la categoría teórica Patriarcalismo. Y considera que éste encuentra en términos históricos, una de sus primeras formulaciones en la separación que en la Grecia clásica se da entre el conocimiento abstracto y el saber práctico o concreto. Esto es, entre los hechos y la vida -lo impuro-, frente a la pureza y la verdad de los principios. El concepto de patriarcalismo tiene que ver con el conjunto de relaciones que articulan un conjunto indiferenciado de opresiones: sexo, raza, género, etnia, y clase social, y con el modo en que las relaciones sociales particulares combinan una dimensión pública de poder, explotación o estatus con una dimensión de servilismo personal. En The social construction of social of black feminist thought, Patricia Hill Collins denuncia los principios en que se basa el patriarcalismo:

a) El principio de dominación. A través de la dominación, las experiencias dominantes se presentan como universales.

b) Principio de complementariedad. El dominado acepta la situación de inferioridad, reforzando su identidad a través del sentimiento inevitable de pertenencia a algo o a alguien. La identificación del grupo oprimido con el poderoso le hace carecer de una interpretación 
propia de su opresión.

c) Principio de necesidad. El grupo naturalizado e inferiorizado que acepta su pertenencia al patrón universalizado, parece que no tiene otra alternativa que vivir desde su propia naturaleza, lo cual les impide tener puntos de vista propios.

d) El principio de victimización. El patriarcalismo hace asumir a los grupos oprimidos la calificación de víctimas, es decir, sujetos pasivos destinados a sufrir inevitablemente las consecuencias del sistema

En efecto, son los feminismos de color, el negro, el chicano, el anarquista y el decolonial (Hernández, 2003), los que nos muestran que las relaciones de opresión que se ciernen sobre los cuerpos de las mujeres se ejercen de manera diferenciada en razón de su género - claro está—, pero también en razón de su clase, raza, heterosexismo. Específicamente, el feminismo anarquista nos muestra el papel central del derecho y del estado en la producción y reproducción de esas opresiones, pues muestra que es mediante el Estado que la violencia social sobre los cuerpos se organiza centralmente, posibilitando así su disección real mediante la disección simbólica; y que es mediante el derecho que esas opresiones son reproducidas, ocultándolas y resignificándolas. Así, en la era moderna, la opresión corpórea de las mujeres tiene sus líneas de manifestación en la idea del Estado, y como base de concreción el monopolio de la violencia del derecho.

El texto del artículo segundo constitucional muestra una imagen deformada de la realidad de la mujer indígena. La primera vez que aparece la imagen del cuerpo de la mujer indígena es,

A. Esta Constitución reconoce y garantiza el derecho de los pueblos y las comunidades indígenas a la libre determinación y, en consecuencia, a la autonomía para:

I. Decidir sus formas internas de convivencia y organización social, económica, política y cultural.

II. Aplicar sus propios sistemas normativos en la regulación y solución de sus conflictos internos, sujetándose a los principios generales de esta Constitución, respetando las garantías individuales, los derechos humanos y, de manera relevante, la dignidad e integridad de las mujeres. La ley establecerá los casos y procedimientos de validación por los jueces o tribunales correspondientes. (CPEUM, Art. 2)

... para sujetarla al grillete autonómico. Grillete porque mediante el discurso legal, y por virtud de este párrafo, el que tiene el poder de decir el derecho la encorseta en el discurso central del estado ocultado la pluralidad jurídica 'realmente existente' limitándola, coaccionándola; pues decide que en el marco de la autonomía, y sólo en el marco de la autonomía que el estado les permite, sus sistemas normativos pueden ser. Así, esta disección somete al cuerpo de la mujer indígena a una cadena de sentido ligado a una 'integridad y dignidad' dependiente de la validación de 'los casos' por los jueces o tribunales correspondientes, connotando así la amenaza de la violencia que el Estado es capaz de desencadenar.

Pero el papel de la mujer en los sistemas normativos indígenas tiene peculiaridades en la reproducción comunitaria que el derecho moderno de la reproducción mercantil invisibiliza, colocando a los sistemas jurídicos indígenas en el plano de la sospecha. En este párrafo, el texto legal introduce la manipulación que sugiere que los sistemas normativos indígenas no respetan 'la integridad y dignidad de las mujeres.' Pero las relaciones familiares ampliadas, las prácticas de cargos comunitarios, la propiedad comunal de la tierra, la vida en comunidad, son 
relaciones que atraviesan a las mujeres indígenas. En cambio, el texto oculta la explotación colonial y el despojo del que son presa los pueblos indígenas, y de la especificidad de su manifestación en los cuerpos de las mujeres. Con este recurso, el texto encubre la violencia racial, de clase y de género con un discurso de reconocimiento, de garantía y de protección de la 'dignidad e integridad'. Así mismo, la segunda vez que el texto hace referencia a la mujer indígena es en el párrafo siguiente, reformado en 2016;

A. Esta Constitución reconoce y garantiza el derecho de los pueblos y las comunidades indígenas a la libre determinación y, en consecuencia, a la autonomía para: [...]

III. Elegir de acuerdo con sus normas, procedimientos y prácticas tradicionales, a las autoridades o representantes para el ejercicio de sus formas propias de gobierno interno, garantizando que las mujeres y los hombres indígenas disfrutarán y ejercerán su derecho de votar y ser votados en condiciones de igualdad; así como a acceder y desempeñar los cargos públicos y de elección popular para los que hayan sido electos o designados, en un marco que respete el pacto federal, la soberanía de los Estados y la autonomía de la Ciudad de México. En ningún caso las prácticas comunitarias podrán limitar los derechos políticoelectorales de los y las ciudadanas en la elección de sus autoridades municipales. (CPEUM, Art. 2)

De nuevo, el texto acude a la ficción de la igualdad jurídica, ocultando las desigualdades 'realmente existentes', poniendo — de nuevo-, a los sistemas normativos indígenas en el plano de la sospecha, con la añadidura de imponer un candado a su realización 'real', pues los pone en el plano de 'derechos' esto es, de concesiones del Estado, sujetándolos a la manifestación del paradigma de la representación política moderna. Así, mediante esta estrategia discursiva, las opresiones traslapadas que pesan sobre las espaldas de las mujeres indígenas son borradas, creando la ilusión de un mundo igualitario. El concepto de 'opresiones traslapadas o planos superpuestos de opresión' defendido por las feministas chicanas hace ver que, si bien la desigualdad de género es el eje vertebrador que recorre todo el espectro de la situación de opresión de la mujer, ésta se va incrementando a medida que atraviesa la realidad en la que cada mujer está inserta. Así, en un otro nivel de opresión se encuentran las mujeres cuya desigualdad de género se recrudece por la discriminación étnica o racial, y, por último, en otro nivel, se sitúan las mujeres que sufren, además, la opresión o discriminación económica. Así, las mujeres son colocadas en planos de desigualdad tanto en relación con los hombres, como en relación con otras mujeres (Anzaldúa, 1998).

Si continuamos con el texto,

B. La Federación, las entidades federativas y los Municipios, para promover la igualdad de oportunidades de los indígenas y eliminar cualquier práctica discriminatoria, establecerán las instituciones y determinarán las políticas necesarias para garantizar la vigencia de los derechos de los indígenas y el desarrollo integral de sus pueblos y comunidades, las cuales deberán ser diseñadas y operadas conjuntamente con ellos. [...]

V. Propiciar la incorporación de las mujeres indígenas al desarrollo, mediante el apoyo a los proyectos productivos, la protección de su salud, el otorgamiento de estímulos para favorecer su educación y su participación en la toma de decisiones relacionadas con la vida comunitaria. (CPEUM, Art. 2)

Pero la concepción lineal del tiempo que implica la idea del desarrollo, así como su visión instrumental de 
la naturaleza, de la vida y de la producción, son manifestaciones del derecho moderno mercantil, ajeno al derecho de los sistemas normativos indígenas y al papel de las mujeres en su reproducción. Precisamente, los más airados debates que han puesto los pueblos indígenas sobre la mesa de la agenda política es la idea del desarrollo como progreso infinito, a costa de la naturaleza y de la vida. De nuevo, aquí, el texto violenta el cuerpo de las mujeres indígenas arrojándolas como instrumento de una concepción de mundo que les es ajena, para luego señalar que,

B. La Federación, las entidades federativas y los Municipios, para promover la igualdad de oportunidades de los indígenas y eliminar cualquier práctica discriminatoria, establecerán las instituciones y determinarán las políticas necesarias para garantizar la vigencia de los derechos de los indígenas y el desarrollo integral de sus pueblos y comunidades, las cuales deberán ser diseñadas y operadas conjuntamente con ellos. [...]

VIII. Establecer políticas sociales para proteger a los migrantes de los pueblos indígenas, tanto en el territorio nacional como en el extranjero, mediante acciones para garantizar los derechos laborales de los jornaleros agrícolas; mejorar las condiciones de salud de las mujeres; apoyar con programas especiales de educación y nutrición a niños y jóvenes de familias migrantes; velar por el respeto de sus derechos humanos y promover la difusión de sus culturas.

Como vemos, el texto naturaliza, de nuevo, el hecho de la migración forzada, la salud mermada y el hambre consecuencia de la situación de desigualdad y exclusión estructural a la que son sometidas, añadiendo el blanqueo del texto con la figura de los derechos humanos y la cultura. Como vemos, el texto presenta las desigualdades reales encubriéndolas con ideologías de reconocimiento, de garantes, y de derechos; pero que, a la vez, distribuyen y diseccionan a los cuerpos de las mujeres indígenas confeccionándolas como instrumento de sospecha y naturalizando su situación de opresiones traslapadas. Formularemos ahora algunas breves consideraciones.

\section{CONSIDERACIONES FINALES}

Al comenzar dijimos que el derecho oculta al tiempo que muestra. Muestra el espejo deforme de una sociedad igualitaria, del reconocimiento de la otredad, del espacio democrático, de la ciudadanía multicultural. Y oculta las heridas reales provenientes de la desigual distribución de las condiciones materiales de existencia, de las diferencias de clase, género, raza. Mediante la construcción de la ficción jurídica, el lenguaje constituye a los sujetos como entes abstractos y universales, borrando las opresiones traslapadas realmente existentes, diseccionado los cuerpos, distribuyéndolos y colocándolos en planos de naturalización del conflicto y de los privilegios de unos sobre otros. Así, los cuerpos de las mujeres indígenas son atravesados por diversas opresiones ocultas en la manifestación de la descripción del discurso del derecho; y en específico, en el discurso legal del artículo segundo constitucional son construidos como instrumentos encorsetados en el grillete autonómico, al tiempo que destruidos naturalizando su situación real de opresión, negándoles de este modo la posibilidad de la vivencia comunitaria. 


\title{
DISCURSIVE DISCLOSURES OF THE BODY OF INDIGENOUS WOMEN IN MEXICAN CONSTITUTIONAL LAW
}

\begin{abstract}
The article proposes to analyze — through the use of semiological resources —, the representation of the body of indigenous women in the Mexican Constitution, from the perspective of the Crítica Jurídica, understood as discursive analysis. Under the premise that the discourse of law shows while hiding, the analysis seeks to reveal the wounds inflicted on the bodies of indigenous women in the legal text, wounds that the discourse of law conceals under a veil of equality, guarantor state, protection and pluricultural citizenship.
\end{abstract}

Keywords: Crítica Jurídica; Semiology; Discourse of law; Indigenous Women; Constitution.

\section{REFERENCIAS}

ANZALDÚA, Gloria. "La prieta” en Moraga, Ch. y Castillo, A. Esta puente, mi espalda, ism press, San Francisco, 1998, p. 157-171.

CORREAS VAZQUEZ, Oscar, Crítica de la Ideología Jurídica, CEIICH—UNAM, Ediciones Coyoacán, segunda edición, México, 2005.

DUQUELSKY, Diego J., "YO, Ovidio González Wasorna, Y el mito de la protección constitucional del derecho indígena”, en Marí, E. (et al.), Materiales para una Teoría Crítica del Derecho, Ed. Lexis Nexis, Segunda edición, Bs. As. 2006

ECHEVERRÍA, Bolívar, Modernidad y Blanquitud, Ediciones Era, México, 2010

GARCÍA LINERA, Álvaro, Forma Valor y Forma Comunidad, Consejo Latinoamericano de Ciencias Sociales, Muela del Diablo editores, La paz, Bolivia, 2009.

HERNÁNDEZ, R. A. (2003): "Posmodernismos y Feminismos: Diálogos, Coincidencias y Resistencias", Desacatos, no 13, invierno, pp. 107-121, Centro de Investigaciones y Estudios Superiores en Antropología Social, México. Disponible en http:// www.redalyc.org/pdf/139/13901308.pdf

HOOKS Bell, Avtar Brah, Chela Sandoval, Gloria Anzaldúa et alt:: Otras inapropiables. Feminismos desde las fronteras, Col. Mapas, Traficantes de Sueños, Madrid. 2004.

HERRERA, Joaquín "De la casa de muñecas al Cyborg: Nuevas metáforas para una Crítica Materialista del Patriarcalismo" en: Crítica Jurídica. Revista Latinoamericana de Política, Filosofía y Derecho, Número 23, 2004.

MARÍ, Enrique, "Racionalidad e imaginario social en el discurso del orden”, en Papeles de filosofía para arrojar al alba, Biblos, Buenos Aires, 1993.

RUIZ, Alicia, "Aspectos ideológicos del discurso jurídico", en Marí, Enrique (et al.), Materiales para una Teoría Crítica del Derecho, Ed. Lexis Nexis, Segunda edición, Bs. As. 2006. 
WEBER, Max, La ética protestante y el espíritu del capitalismo, FCE, México, 2011.

Trabalho enviado em 12 de janeiro de 2018.

Aceito em 31 de janeiro de 2018. 